\title{
A PERCEPÇÃO DO CARDIOPATA FRENTE À CIRURGIA CARDÍACA ${ }^{1}$
}

[Cardiac patients' perception facing a cardiac surgery]

\author{
Evelin Loss* \\ Maria de Fátima Mantovani**

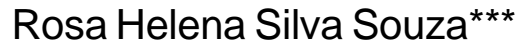

RESUMO:Trata-se de um estudo qualitativo, realizado em um hospital de pequeno porte da cidade de Curitiba, no período de novembro de 2003 a janeiro de 2004, com objetivo de apreender a percepção do cardiopata frente a cirurgia cardíaca. Os dados foram coletados mediante entrevista semi-estruturada, realizada na Unidade de Internação durante o pós-operatório, com 4 clientes. A análise dos depoimentos permitiu-nos identificar 5 categorias: a percepção da finitude, evidenciada pelo sentimento de aproximação da morte: a vulnerabilidade frente à doenças e situações de risco; a percepção da tecnologia como resgate da vida, após o enfrentamento da intervenção cirúrgica; o desejo de ter qualidade de vida; e o repensar de valores, mostrando a necessidade de dar um novo sentido à vida. O doente cardíaco, foco deste estudo, não percebe seu processo de adoecimento, e, ao constatar a necessidade de cirurgia cardíaca, vivenciou momentos de reflexão e expectativa, fato que mostra a importância de uma assistência de enfermagem voltada ao ser biopsicossocial.

PALAVRAS-CHAVE: Cirurgia Cardíaca; Enfermagem Perioperatória; Percepção.

\footnotetext{
${ }^{1}$ Extraído de Monografia de Conclusão do Curso de Graduação em Enfermagem da Universidade Federal do Paraná.

* Acadêmica do Curso de Graduação em Enfermagem da UFPR.

** Profa Adjunto do Departamento de Enfermagem da UFPR. Dra em Enfermagem pela USP/SP. Coordenadora do Grupo Multiprofissional em saúde do Adulto (GEMSA)

*** Enfa Mestranda do Curso de Pós-Graduação em Enfermagem da UFPR. Membro do GEMSA
}

\section{INTRODUÇÃO}

O contexto em que o homem está inserido, vem se modificando nos últimos tempos; mudanças no estilo de vida, que se originaram do avanço tecnológico e científico, trouxeram consigo novos comportamentos e muitas descobertas. $\mathrm{Na}$ área da saúde, este avanço vem permitindo a cura de diversas doenças, mas também, em decorrência de mudanças dos hábitos alimentares, do sedentarismo e de maior exposição a fatores de risco como fumo, álcool, stress, favorecendo o surgimento de outras enfermidades.

Nesse novo cenário, as doenças crônicas não transmissíveis vêm ganhando espaço em detrimento das doenças agudas, interferindo na qualidade de vida das pessoas. Elas se caracterizam por uma história natural prolongada, com multiplicidade de fatores de risco, pois em sua constituição há interação de fatores etiológicos e biológicos conhecidos e desconhecidos, curso clínico prolongado e permanente e manifestações clínicas com períodos de remissão e exacerbação evoluindo para graus variados de incapacidade e morte (LESSA, 1998).

A condição crônica de saúde, pode surgir a qualquer momento na vida do indivíduo, alterando seu modo de viver e o das pessoas que convivem com ele (TRENTINI, 1992), trazendo consigo estressores, como tratamento prolongado e/ou permanente, mudanças no estilo de vida e no meio social. O modo como agimos frente a esta nova situação, é o que chamamos de processo de enfrentamento (TRENTINI; SILVA, 1992).

As pessoas podem enfrentar sua condição crônica, procurando utilizar-se dos recursos que 
possuem, obtendo maiores informações a respeito da doença e adaptando-se a um novo estilo de vida, na tentativa de diminuição desses estressores.

Entre as enfermidades crônicas, as doenças cardiovasculares tem um papel de destaque, pois o perfil epidemiológico da população brasileira, nos mostra como primeira causa de mortalidade, as doenças do aparelho circulatório. Segundo o Ministério da Saúde (BRASIL, 2003), elas são responsáveis por 31,1\% dos óbitos do país.

As doenças cardíacas podem ocorrer através de várias manifestações clínicas; a mais comum é a doença coronária, que pode provocar tanto a isquemia do músculo miocárdico, quanto arritmias e insuficiência cardíaca. A forma mais conhecida de doença isquêmica é o infarto agudo do miocárdio, que é o maior responsável por mortes em todo o mundo (LESSA, 1998).

Associado pelas pessoas ao amor e ao romantismo de uma maneira geral, o coração realiza seu trabalho eficiente e contínuo, sem dar mostras de cansaço. Estilo de vida e fatores de stress agem diretamente sobre ele, podendo modificar sua estrutura e funcionamento aos poucos, até que de repente ele dá sinais de adoecimento.

Muitas vezes, a pessoa deixa esses sinais sutis passarem despercebidos no corre-corre diário, relegando-os a segundo plano, acreditando ser apenas um cansaço, uma ansiedade, um mal-estar. E o humilde coração continua executando seu trabalho, porém já não com tanta presteza, apresentando sinais de uma insufuciência cardíaca, aterosclerose, isquemia. Até que um dia se rebela e infarta, mostrando que algo realmente não está bem e precisa urgentemente ser revisto; ou pode até parar para sempre, quando não tem mais jeito.

A iminência de um infarto faz com que a pessoa repense alguns aspectos de sua vida e os modifique, passando a ter uma alimentação mais equilibrada; a fazer exercícios físicos e torne o cigarro e outros afins, coisas do passado. Mas nem sempre é fácil alterar esses pequenos hábitos. Dependendo dos danos, ela é submetida a um procedimento cirúrgico delicado, de risco e repleto de incertezas. A superação desta etapa é seguida do processo de reabilitação e de mudanças sociais, fazendo renascer uma nova consciência de vida.

Devemos deixar claro que o coração sadio é um órgão que deve ser preservado, pois controla nossa circulação corporal e ainda realiza sua própria nutrição. Ele gera seus impulsos elétricos para continuar batendo e também os controla para manter um ritmo adequado.

Na prática médica, freqüentemente se observa doenças cardiovasculares, seja sob forma aguda nos serviços de emergência, ou com manifestações de insuficiência cardíaca nos exames de rotina. Conforme RIBEIRO \& MANTOVANI (2001), um dos sintomas mais importantes para detecção de doença cardiovascular, é a dor torácica, que na maioria das vezes passa despercebida, entendida como algo sem importância. O indivíduo não valoriza o auto-cuidado para o controle do seu processo crônico de adoecimento, o que ocasiona várias re-internações hospitalares e o agravo do seu estado geral de saúde.

Segundo WIZIACK (1999), pessoas a partir dos 40 anos sofrem um aumento no estresse cotidiano, diminuem a prática de exercícios físicos, modificam a dieta alimentar e são tabagistas, aumentando com isso a possibilidade de apresentar episódios de dor torácica.

Um indivíduo que de repente sofre um infarto e se vê obrigado a realizar um procedimento cirúrgico, passa por situações adversas, se percebendo doente, sem ter acompanhado seu processo de adoecimento, que pode ter ocorrido de maneira silenciosa; e ainda vivencia a experiência de realizar uma cirurgia cardíaca, que também traz várias implicações ao seu processo de vida.

Viver significa estar em constante interação com o mundo, se adaptando ao meio e sofrendo mudanças. O processo saúde-doença é complexo e percebido de maneira particular a cada um; acontecendo de diversas maneiras, interage com o ambiente natural do indivíduo.

A saúde seria o processo e produto da satisfação de necessidades de bem-viver e de bemestar dos seres humanos, relacionada à qualidade de vida desejada, esperada pelas pessoas, enquanto indivíduo e coletivo (PATRÍCIO, 1999).

O adoecimento, é um processo que nos leva a refletir sobre a totalidade do homem, relacionandose com os outros homens e com a vida de modo geral. Atravessa o curso natural da vida e por vezes nos deixa numa atitude expectante (SILVA, 2001). 
No mesmo instante em que o indivíduo pensa estar saudável, seu organismo pode apresentar indícios de que algo não vai bem e demonstrar uma situação caracterizada por doença. Observa-se então, que a doença surge rapidamente, e, muitas vezes, este indivíduo passa a apresentar sinais alarmantes de descompensação, aparentemente abrupta, mas que possui uma história que foi desconsiderada.

Entre estas descompensações, registram-se as doenças cardiovasculares como uma das principais causas de morte, que atinge tanto a indivíduos jovens quanto idosos. Frente a essa realidade, optamos por trabalhar a questão do adoecimento e do enfrentamento desse processo e da modificação da qualidade de vida experimentada com a realização da cirurgia cardíaca; seja pela experiência do infarto, ou pela necessidade da revascularização do miocárdio.

A cirurgia cardíaca é uma das mais temidas pelo homem, devido ao simbolismo atribuído ao coração. Sendo assim, nosso objetivo neste estudo foi identificar a percepção do doente cardíaco frente à cirurgia cardíaca.

\section{TRAJETÓRIA METODOLÓGICA}

Trata-se de um estudo qualitativo, extraído de uma monografia de conclusão do Curso de Graduação em Enfermagem da Universidade Federal do Paraná, desenvolvido com doentes na Unidade de Terapia Intensiva (UTI) de um hospital de pequeno porte da cidade de Curitiba, que possui um leito exclusivo para pós-operatório de cirurgia cardíaca e seis leitos para as demais especialidades.

Os sujeitos do estudo foram quatro adultos do sexo masculino, com idade entre 50 a 80 anos, residentes em Curitiba, em pós-operatório de cirurgia cardíaca, acompanhados durante sua permanência na UTI e posteriormente na Unidade de Internação, no período de novembro de 2003 a janeiro de 2004.

Para conhecimento do fenômeno foram realizadas entrevistas semi-estruturadas, com gravação dos depoimentos dos sujeitos em fita cassete, para posterior análise das descrições e publicação dos resultados. As entrevistas ocorreram na Unidade de Internação durante o período pósoperatório e tiveram como provocação inicial as seguintes questões:

- Descreva para mim, como foi para o senhor (a) descobrir que estava doente.

- O que representa para o senhor (a) ter realizado uma cirurgia cardíaca? diante?

- O que espera para a sua vida daqui em

Os discursos foram transcritos na íntegra, analisados e agrupados em recortes, o que possibilitou identificação das categorias para análise dos mesmos.

Durante todo o processo as questões éticas foram obedecidas e respeitadas, atendendo a Resolução 196/96, que normatiza as pesquisas que envolvem seres humanos. Foi explicitado a cada participante o objetivo da pesquisa, entregue 0 termo de consentimento livre e esclarecido para que tomassem ciência, e, após a leitura do mesmo, o assinassem. Nestes termos, asseguramos aos sujeitos da pesquisa a manutenção de sigilo e anonimato das informações.

\section{APRESENTAÇÃO E ANÁLISE DOS DISCURSOS}

\subsection{COMPOSIÇÃO DO GRUPO, SEGUNDO OS ASPECTOS BIOSSOCIAIS.}

Consideramos os aspectos biossociais: sexo, idade, estado civil, escolaridade, situação de trabalho e religião, para análise e caracterização dos sujeitos. A análise possibilitou a observação de que os quatro sujeitos que participaram do estudo eram do sexo masculino; casados; com idade média de 65 anos; três católicos e um evangélico; dois cursaram ensino médio e dois cursaram ensino superior.

A predominância do sexo masculino foi casual, em virtude das pacientes do sexo feminino terem recebido alta hospitalar em momentos que não tínhamos disponibilidade para realizar a entrevista ou, em alguns casos, terem ido a óbito. Foram realizadas aproximadamente 20 cirurgias cardíacas durante o período em que realizamos este estudo.

Dos participantes, 3 são aposentados e 1 
ainda exerce atividade remunerada. A aposentadoria de certa forma contribui para o processo de adoecimento, porque segundo WIZIACK apud RIBEIRO \& MANTOVANI (1999), pessoas a partir dos 40 anos sofrem um aumento no estresse cotidiano, mudando seus hábitos, modificando sua dieta alimentar e diminuindo os exercícios físicos.

\subsection{DISCUSSÃO E COMPREENSÃO DOS DISCURSOS}

Após a análise dos depoimentos, evidenciamos 5 categorias, que são: a finitude; a vulnerabilidade à doença; a tecnologia como resgate da vida; em busca de qualidade de vida e o repensar de valores, que a seguir, serão expostas com trechos dos discursos. Os sujeitos do estudo foram identificados com as cores azul, cinza, verde e branco.

\subsubsection{AFINITUDE}

\begin{abstract}
"Uma sensação assim de ter chegado perto da morte, imaginar o coração parado, sensação de choque..." (AZUL)

" $A$ vida acabou...daqui para frente esperar chegar meu dia... morrer..." (CINZA)
\end{abstract}

Nestes trechos, podemos observar que a morte é a representação da finitude, de que tudo vai acabar, de que não há esperança, levando a angústia da experiência desconhecida e rica de simbolismos e significados.

O medo da morte é inerente ao desenvolvimento humano, é um medo do desconhecido, somado ao medo da extinção, das perdas afetivas, da solidão e do sofrimento. Mesmo tendo passado por um processo de alto risco, superado o difícil e demorado processo de reabilitação, a morte surge não como uma idéia apavorante, mas como uma conseqüência natural do processo de viver.

A morte pode ser vista como um mistério incompreensível, ou então um absurdo inaceitável; é tratada como um tabu, assunto do qual as pessoas não gostam de falar; apesar de terem a consciência de que é uma etapa da vida com a qual deve-se conviver. Ela também pode ser encarada de uma maneira positiva, pois, para algumas pessoas a morte é nada, é ausência completa de angústias, fim das aflições. Trata-se de uma passagem, uma transição desta vida para outra, mais plena e mais feliz (VOMERO, 2002).

\subsubsection{A VULNERABILIDADE À DOENÇA}

Surge no cliente que não tem uma idéia formada sobre seu processo de adoecimento. Ele não se sentia doente, não percebeu a evolução do seu estado; apenas se deu conta quando teve em mãos, resultados de exames que confirmaram o diagnóstico.

"Acontece pra mim, acontece pra você e acontece pra qualquer um..." (VERDE)

Por não perceber seu estado, a pessoa vai convivendo com os sintomas, na maioria das vezes sutis, tentando "amenizá-los", mas chega o momento em que a intensidade dos sintomas aumenta e impõe a busca de solução imediata (MANTOVANI, 2001).

O adoecimento é sentido pelo doente mediante o contato com a dor e o sofrimento, abalando o seu projeto de vida; acarretando mudanças psicológicas e sociais; ameaçando sua integridade física.

Ao perceber-se vulnerável à doença, defronta-se com um estressor, que passa a ter um significado em sua vida, junto com um processo cognitivo e emocional de apreciação e decisão (TRENTINI, 1992).

\subsubsection{ATECNOLOGIA COMO RESGATE DA VIDA}

Em contrapartida à situação da morte, percebemos nos discursos que enfrentar a cirurgia e ter um bom processo de reabilitação possibilita um sentimento de prazer inesperado pelo vencimento de uma etapa importante. $O$ depoimento a seguir, ilustra essa afirmação:

"Mas maravilhado com a tecnologia...fiquei
impressionado com a rapidez da recuperação..." (AZUL)

A tecnologia é apontada como solução do problema graças à ela tudo é possível e tudo pode ser resolvido. O que nem sempre podemos aceitar 
como verdadeiro, porque ao mesmo tempo em que aumenta o desenvolvimento científico, a esperança e a qualidade de vida, aumenta a expectativa de vida da população e, conseqüentemente, as condições crônicas de saúde (MANTOVANI et al, 2001).

A tecnologia permitiu avanços no tratamento dos indivíduos com isquemia cardíaca. A cirurgia de revascularização do miocárdio tem como objetivos: prolongar a vida, promover alívio da dor e melhorar a qualidade de vida (DANTAS et al, 2001).

"Sair de uma dessas, é uma vitória..." (BRANCO)

Às vezes, sentir-se doente, enfrentar um processo de alteração do corpo que resulta na redução das capacidades ou na diminuição da expectativa de vida, faz com que o indivíduo tenha oportunidade de enxergar novos caminhos, determinar prioridades, aprofundar significados e valores de vida (SASSO, 1992). Então o doente cardíaco sente-se vitorioso ao passar pelo processo cirúrgico e ter sucesso na sua recuperação.

\subsection{EM BUSCA DE QUALIDADE DE VIDA}

Dentro da temática dos depoimentos aparece o desejo de melhorar a qualidade de vida, citado nesta fala:

"Espero uma qualidade de vida melhor..."

Conforme Gaíva (1998), qualidade de vida é um conceito bastante amplo que envolve diversos fatores, se relaciona com as condições ambientais, sociais e emocionais da vida de cada um de nós. Para Gonzales (1993), ela baseia-se em capacidade funcional, nível sócio-econômico e satisfação pessoal.

A qualidade de vida tem significados individuais, sentida por cada indivíduo com determinado grau de intensidade e de valores das coisas. Hornquist (1990), definiu como determinantes da "qualidade de vida": indicadores orgânicos, que são saúde e estado funcional; indicadores psicológicos, que são auto-estima, identidade, aprendizado e conhecimentos; indicadores sociais, que são relacionamento, vida familiar e vida sexual; indicadores comportamentais, que são hábitos, lazer, vida profissional e capacidade de auto-cuidado; indicadores materiais, que são renda, habitação, economia privada e capacidade para se manter; e os indicadores estruturais, que são posição social e significado da própria vida.

Esses fatores norteiam o que combinado pode ser considerado como qualidade de vida, embora seja difícil avaliá-la, pois nada mais é do que a convergência do subjetivismo de cada indivíduo.

Infere-se que nossos clientes têm qualidade de vida, uma vez que possuem condição financeira estável; bom nível de instrução, que Ihes permite compreender de maneira satisfatórias suas necessidades e podem usufruir de um plano de assistência médica privada, que permite a realização das intervenções médico-hospitalares necessárias.

Ultimamente, com a predominância das doenças crônicas, que alteram as condições objetivas e subjetivas do indivíduo e da sua família, a forma como ele vivencia as transformações do seu processo de adoecimento influenciam diretamente na sua qualidade de vida. É importante na área de saúde refletir sobre esse aspecto, porque os avanços na Medicina, tem proporcionado quedas nas taxas de mortalidade e aumento na expectativa de vida (GAÍVA, 1998).

\subsection{O REPENSAR DE VALORES}

Nesta categoria, observamos a dedicação total à família; e a volta à vida normal.

"Porque esse tipo de coisa nos faz repensar a vida
de um modo geral...visão dos valores das coisas..." (AZUL)

Ao nos sentirmos inseguros, em situação de risco, começamos a repensar alguns aspectos da nossa vida. Realizamos uma revisão de vida, pensamos nas pessoas que estimamos e encontramos forças para enfrentar essa nova situação, é o que chamamos de processo de enfrentamento. Todo processo de enfrentamento, sofre influência das experiências de vida que herdamos, o jeito que encaramos nossa condição, pode reduzir e até mesmo minimizar os estressores envolvidos (TRENTINI, 1992). 
"Daqui em diante, eu quero levar uma vida normal...olha se eu tiver vontade de fazer alguma coisa e tiver condições, eu tô fazendo..." (VERDE)

A aproximação de uma situação limite, desperta a vontade de mudanças de hábitos, antes deixados de lado ou considerados sem importância. Recaímos nos indicadores comportamentais que incluem: lazer e capacidade de auto-cuidado. A vida é vista sob nova perspectiva, na qual são incluídos além dos deveres diários, momentos de se realizar algo prazeroso, que tenha um novo sentido.

A qualidade de vida é novamente percebida e manifestada aqui como vontade de levar uma vida normal, dedicar-se à família e necessidade de lazer. A cirurgia desperta a perspectiva de revisar os valores das coisas e estabelecer novas prioridades. O importante é viver bem, com qualidade e não apenas sobreviver.

\section{CONSIDERAÇÕES FINAIS}

Na análise dos depoimentos, identificamos 5 categorias que contemplam a perspectiva de ter realizado uma cirurgia cardíaca. A primeira categoria é a percepção da finitude, que é a aproximação com a morte e o que ela representa; a segunda categoria é a percepção da vulnerabilidade à doença, sentida ao se deparar com a doença e estar frente a uma situação limite; como terceira categoria temos a percepção da tecnologia como resgate da vida, momento em que é observada a evolução da ciência e tecnologia a serviço do tratamento das doenças, mesmo que este seja uma cirurgia, vista com algo difícil e assustador; em seguida vem a manifestação do desejo de uma qualidade de vida melhor e por fim ocorre o repensar de valores, uma nova percepção do que é realmente importante.

Acreditamos que conseguimos alcançar o objetivo proposto no início deste estudo, que era apreender a percepção do doente cardíaco frente à cirurgia, pois obtivemos resultados que vão ao encontro com o perceber a morte, suscetibilidade à doença, a vitória, a esperança de melhora e por fim a consciência da necessidade de mudanças.

O doente cardíaco, foco desse estudo, não percebe seu processo de adoecimento e mediante o aparecimento dos sintomas e os resultados de exames, constata a existência de uma patologia cardíaca e necessita de intervenção cirúrgica.

Enfrenta uma situação bastante importante em sua vida - a cirurgia cardíaca. Um momento que o leva a experimentar diversas sensações e expectativas, despertando sentimentos e reações.

A cirurgia cardíaca é revestida de vários simbolismos desenvolvidos pela crença popular. Ter que operar o coração é algo muito sério...oferece risco de vida alto...é dolorido e de difícil recuperação. Essa percepção gera conflitos e faz com que o doente cardíaco perceba a nova realidade a ser enfrentada - a cirurgia, sob diversos aspectos.

Considerando a magnitude do problema estudado, acreditamos ser importante para uma assistência de enfermagem, olhar além do corpo físico do cardiopata candidato a cirurgia cardíaca, um doente considerado crônico, que necessita de cuidados individualizados e permanentes, e buscar desnudar seus sentimentos, percebendo suas necessidades, conflitos, angústias e expectativas em relação ao seu processo perioperatório.

\section{REFERÊNCIAS}

BRASIL. Ministério da Saúde - DATASUS. Óbitos por Ocorrência por Capítulo CID-10, segundo Região: IX Doenças do aparelho circulatório, período de 2000. Disponível: <http:// tabnet.datasus.gov.br/cgi/tabcgi.exe?sim/cnv/ obtuf.def>. acesso em 17 de novembro de 2003.

DANTAS, R. A. S. ; AGUILLAR, O. M. ; BARBEIRA, C. B. S. Retorno às atividades ocupacionais e sexuais após cirurgia de revascularização do miocárdio. Rev. Latino-Am. Enf., Ribeirão Preto, v. 9 , n. 4 , p. 26-31, jul. 2001.

GAÍVA, M. A. M. Qualidade de vida e saúde. Rev. Enf. UERJ, Rio de Janeiro, v. 6, n. 2, p. 377-382, dez. 1998.

IDE, C. A. C. ; CHAVES, E. C. A questão da determinação do processo saúde-doença. Rev. Esc. Enf. USP, São Paulo, v. 24, n. 1, p. 163-167, abr. 1990.

LESSA, I. $\mathbf{O}$ adulto brasileiro e as doenças da modernidade: epidemiologia das doenças crônicas não-transmissíveis. São Paulo - Rio de 
Janeiro: Hucitec Abrasco, 1998.

MANTOVANI, M. F. Sobrevivendo: o significado do adoecimento e o sentido da vida pós-ostomia. São Paulo, 2001. Tese (doutorado) - Universidade Estadual de São Paulo.

PATRÍCIO, Z. M. Métodos qualitativos de pesquisa e de educação participante como mediadores na construção da qualidade da vida novos paradigmas, outros desafios e compromissos sociais. Texto \& Contexto Enf., Florianópolis, v. 8, n. 3, p. 53-77, set./dez. 1999.

RIBEIRO, D. S; MANTOVANI, M. F. Caminhando para a cronicidade: as representações do adoecimento em adultos com dor torácica aguda. Cogitare Enferm., Curitiba, v.6, n.1, p 97-104, jan./ jun. 2001.
SASSO, G. T. M. Compreendendo o ser saudável através do processo saúde-doença. Texto \& Contexto Enf., Florianópolis, v.1, n.2, p.120-138, jul./dez. 1992.

TRENTINI, M.; SILVA, D. G. V. Condição crônica de saúde e o processo de ser saudável. Texto \& Contexto Enf., Florianópolis, v.1, n.2, p.76-88, jul./ dez. 1992.

VOMERO, M. F. Morte. Revista Superinteressante. Editora Abril, ed. 173, p. 3644, fev. 2002.
ENDEREÇO DOSAUTORES: R. Rio Iriri, 20 - bl. 1, ap. 21 Curitiba / PR 82840-310 Fone: 367-9508 